Article

\title{
New Proposal for Flexural Strengthening of Reinforced Concrete Beams Using CFRP T-Shaped Profiles
}

\author{
Renata Kotynia ${ }^{*}{ }^{\dagger}$ and Szymon Cholostiakow ${ }^{\dagger}$ \\ Received: 8 August 2015; Accepted: 16 November 2015; Published: 24 November 2015 \\ Academic Editors: Alper Ilki and Masoud Motavalli \\ Lodz University of Technology, al. Politechniki 6, 90-924 Lodz, Poland; szymon.cholostiakow@p.lodz.pl \\ * Correspondence: renata.kotynia@p.lodz.pl; Tel.: +48-42-631-38-70; Fax: +48-42-631-35-84 \\ + These authors contributed equally to this work.
}

\begin{abstract}
The purpose of this study was to evaluate the performance of a novel strengthening system using T-shaped carbon fiber reinforced polymer (CFRP) profiles. The proposed system successfully combines the advantages of two established strengthening techniques, namely the near surface mounted (NSM) and externally bonded (EB) methods. The paper presents the experimental results of structural tests carried out on seven flexurally-strengthened and two non-strengthened full-scale reinforced concrete (RC) members. Two T-shaped profiles having heights of 15 and $30 \mathrm{~mm}$ were applied. The main parameters of concrete strength and composite strengthening ratio were investigated to evaluate the efficiency of the proposed flexural strengthening system. All specimens were tested under a quasi-static six-point bending configuration. The test results showed a significant increase in the load bearing capacity and the stiffness of the RC beams with strengthening and also a notable reduction in maximum deflections. The high tensile strength utilization of the CFRP profiles places this strengthening technique as a promising alternative to other, less structurally-efficient systems.
\end{abstract}

Keywords: flexural strengthening; CFRP; T-shaped profiles; near surface mounted reinforcement; stiffness; intermediate crack debonding

\section{Introduction}

Structural strengthening of existing reinforced concrete (RC) structures has become a common alternative for rehabilitating deteriorated structures. In selecting strengthening solutions, lightweight materials and resistance to corrosion are recommended. One of the most competitive materials having high mechanical and durability performance is designated as carbon fiber reinforced polymer (CFRP) strips and/or sheets externally bonded (EB) to the concrete surface. Such materials serve as supplemental external reinforcement resisting a portion of the tensile forces from the structure. Many experimental and theoretical studies indicate the benefits of flexural strengthening with EB-CFRP, which has become relatively common in the last decades. EB-CFRP, however, is often limited by intermediate crack debonding (ICD) of the CFRP material from the concrete surface limiting the CFRP strain utilization to approximately $35 \%$ of the available tensile strain [1]. The CFRP utilization can be improved by providing additional mechanical anchorages as reported in [2,3]. Another solution to improve the strength utilization of EB composites is to pretension the material.

The low utilization of FRP tensile strength has prompted the investigation of more effective solutions in terms of strengthening performance. Since the key parameter limiting the CFRP effective strain in the EB technique is the CFRP-to-concrete bond behavior, a technique-known as the near surface mounted (NSM) strengthening technique-based on gluing FRP reinforcement into thin 
slots cut in the concrete cover of the RC members, has been proposed [4-9]. NSM applications consisting of bonding round or square FRP cross sections (bars or strips) with epoxy-based adhesive has been extensively examined for flexural strengthening of RC beams and slabs [10-21]. The NSM technique significantly increases the load bearing capacity and the FRP tensile strain utilization up to $80 \%$ [17,22-24]. The depth of NSM applications is limited to the concrete cover. Going beyond the cover risks cutting transverse reinforcement which, while not affecting the flexural capacity of the member $[17,25,26]$, may be detrimental in terms of reducing concrete confinement or the available ductility in RC slabs [27]. Moreover, cutting stirrups in RC members limits the use of the NSM technique under conditions of cyclic or seismic loads. Finally, flexural strengthening using rectangular NSM strips is limited by the initial deflections of the RC member affecting the ability to develop sufficient bond.

State-of-the-art reviews of flexural strengthening of RC members with NSM FRP reinforcement are provided in $[15,18,23]$. Effects of several parameters such as geometry, steel, and CFRP reinforcement ratios, modulus of elasticity, concrete strength, and depth of the FRP reinforcement were discussed in terms of the failure modes, strengthening efficiency, and FRP strain utilization.

Two of the most commonly expected failure modes of RC beams strengthened in flexure with NSM FRPs are the intermediate crack debonding (ICD) of the FRP reinforcement with adjacent concrete cover separation (CCS) and FRP rupture (R). Rupture, clearly indicates the greatest FRP strain utilization and NSM strengthening efficiency. The concrete crushing (CC) failure followed by yielding of the longitudinal steel reinforcement, recognized as a ductile failure mode typical of flexural failure, may occur in over-reinforced specimens.

On the other hand, epoxy splitting (ES) is confirmed as a premature failure mode, which indicates poor strengthening efficiency $[23,26]$. ES failure or FRP debonding from the epoxy resin are indications of a low epoxy tensile strength (lower than the concrete strength). ES is also observed to occur when the NSM slot width is large.

Combining both EBR and NSM techniques, the novel system of using T-shaped CFRP profiles (named T-NSM) has been proposed and successfully applied for flexural strengthening of RC beams at the Lodz University of Technology (TUL). The T-shaped profile consists of a vertical web, which is bonded into the longitudinal slot cut in the concrete cover and the horizontal flange of the profile which is externally bonded to the concrete surface.

The novelty of this strengthening technique relates to the use of T-section CFRP profiles in lieu of the classic NSM and EB CFRP strips. The T-section area is 4.4 and 1.5 times greater than the cross section area of typical NSM and EBR strips, respectively. The T-NSM system also provides much more bond area between the FRP and the concrete surface. Additionally, the flange of the T-section imparts greater stiffness and allows better control of the profile during the strengthening process. One of the main goals of the presented research is to demonstrate the application and performance of such T-NSM systems using CFRP T-section profiles.

\section{Experimental Program}

An experimental program consisting of nine $550 \mathrm{~mm}(\mathrm{~d}) \times 270 \mathrm{~mm}(\mathrm{w})$ specimens simply-supported RC beams having a clear span of $4000 \mathrm{~mm}$ was carried out in the laboratory of the Department of Concrete Structures in the Lodz University of Technology. The specimens were cast in two series having concrete compressive strength classes of C30/37 and C50/60, respectively.

The beams were reinforced with two $14 \mathrm{~mm}$ diameter steel bars (reinforcement ratio $\rho_{\mathrm{s}}=0.22 \%$ ) in tension and two $12 \mathrm{~mm}$ diameter steel bars in compression. Vertical reinforcement consisting of $8 \mathrm{~mm}$ bars at $100 \mathrm{~mm}$ spacing in each shear span and at $200 \mathrm{~mm}$ spacing in the middle $1200 \mathrm{~mm}$ constant moment region were provided. Bent $14 \mathrm{~mm}$ bars were used as additional shear reinforcement in the support regions to prevent shear failure (Figure 1).

The second investigated parameter (after concrete strength) was the ratio of CFRP reinforcement added $\left(\rho_{\mathrm{f}}\right)$; this varied from $0.11 \%$ to $0.32 \%$. The CFRP T-shaped profiles had $4 \mathrm{~mm}$ thick webs, $3.5 \mathrm{~mm}$ 
thick flanges and were cut to web heights of either 15 or $30 \mathrm{~mm}$ (Figure 2c). The RC beams were strengthened with one or two T-shaped profiles (Figure 2a,b) of either 15 or $30 \mathrm{~mm}$ depth (denoted T15 and T30, respectively). Application of the deeper $30 \mathrm{~mm}$ profiles required cutting the steel stirrups (Figure 2b). As noted previously, cutting the stirrups should be avoided, however because this is possible (either intentionally or inadvertently) in practice, the authors decided to investigate this effect on the flexural behavior of the strengthened beams in this experimental program. In this program, the strengthened beams were over-reinforced in shear with the additional $14 \mathrm{~mm}$ bent bars (Figure 1). The high shear reinforcement ratio prevented the stirrups from reaching high stresses. Nonetheless, it should be emphasized that in RC members under-reinforced in shear, the stirrups should never be cut to accommodate NSM reinforcement [27].

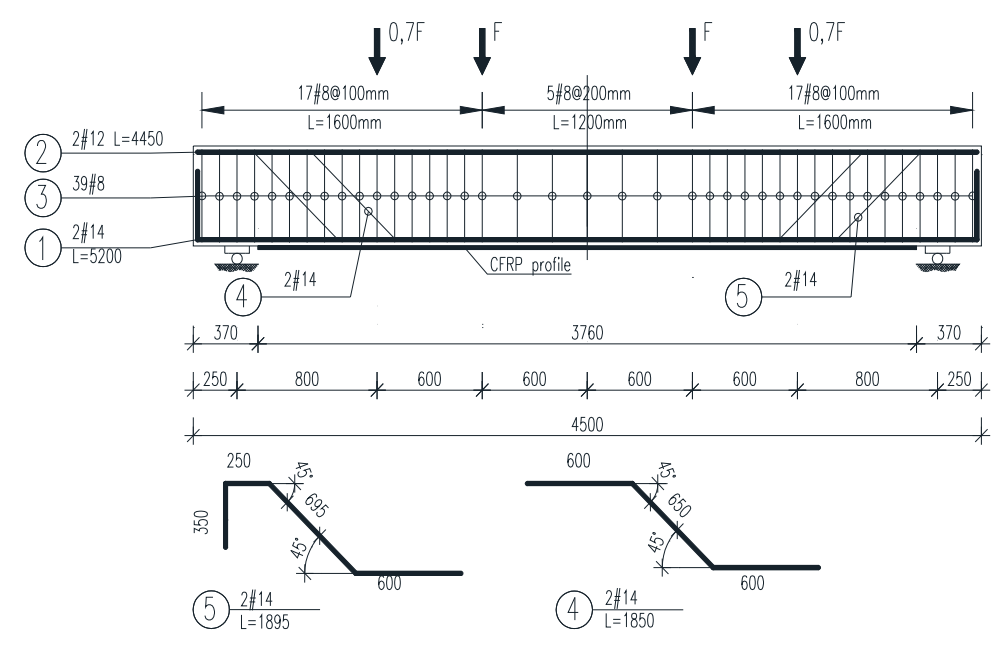

Figure 1. Test arrangement and steel reinforcement of tested beams (dimensions in $\mathrm{mm}$ ).

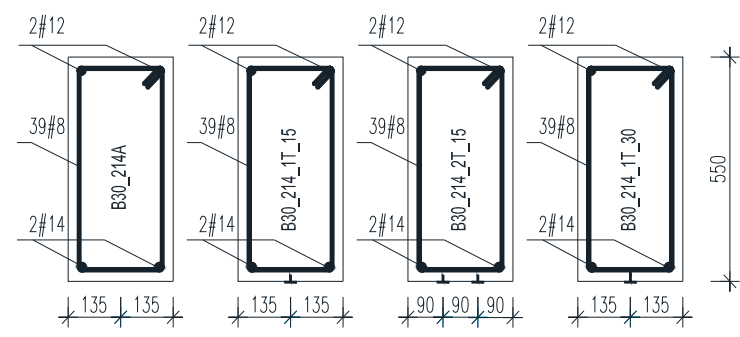

(a)

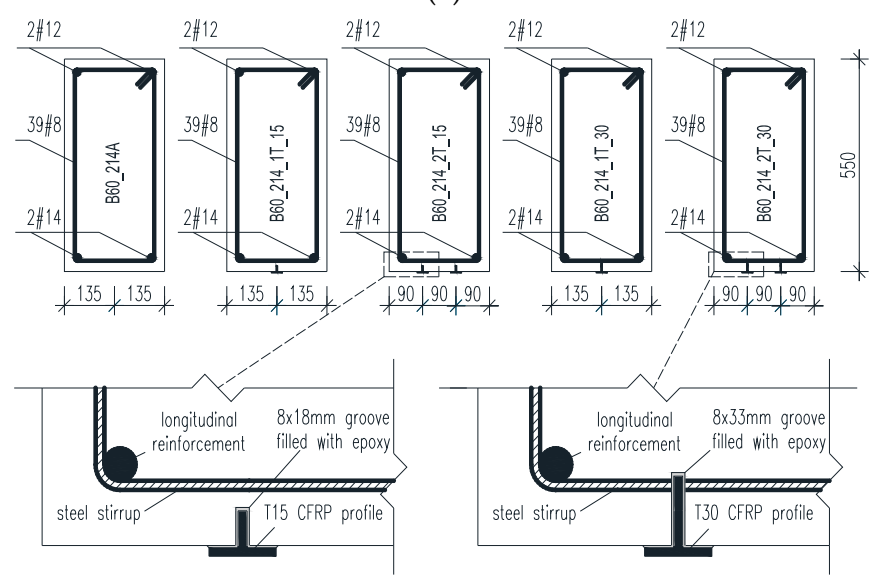

(b)

Figure 2. Cont. 


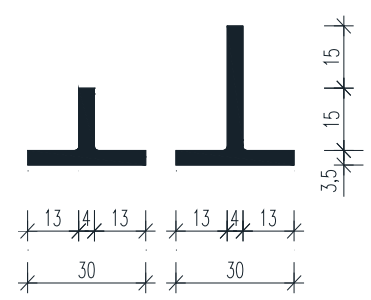

(c)

Figure 2. (a) Strengthening configurations of the beams series $\mathrm{C} 30 / 37$; (b) C50/60; (c) geometry of carbon fiber reinforced polymer (CFRP) profiles (dimensions in $\mathrm{mm}$ ).

Beams were cast in two series using different concrete mixtures (B30 and B60). One reference beam in each series was left un-strengthened as indicated by the symbol " $\mathrm{A}$ " (B30-214A and B60-214A). The remaining beams were strengthened using different configurations of the CFRP profiles (Figure 2a,b). Each beam designation (Figure 2, Table 1) indicates: concrete strength (B30 for concrete $\mathrm{C} 30 / 37$ and $\mathrm{B} 60$ for C50/60 class); "214" for two $14 \mathrm{~mm}$ tensile reinforcing bars; and the CFRP T-shaped reinforcement. For example, beam B30-214-2T-30 identifies the beam as made of class C30/37 concrete, reinforced with two $14 \mathrm{~mm}$ diameter bars and strengthened with two T-shaped CFRP profiles having $30 \mathrm{~mm}$ web heights. The embedment length of all CFRP profiles was equal to $3760 \mathrm{~mm}$ (Figure 1).

Table 1. Characteristic of reinforced concrete (RC) members.

\begin{tabular}{|c|c|c|c|c|c|}
\hline Series & NO. & Symbol & Tensile reinforcement & $\begin{array}{l}\text { Designed compressive cubic } \\
\text { concrete strength, } f_{\mathrm{c}, \mathrm{cube}}\end{array}$ & CFRP profile \\
\hline \multirow{5}{*}{ C30/37 } & & & \multirow{5}{*}{$2 \times 14$} & \multirow{5}{*}{30} & \\
\hline & 1 & B30-214-A & & & - \\
\hline & 2 & B30-214-1T-15 & & & $1 \times \mathrm{T} 15$ \\
\hline & 3 & B30-214-2T-15 & & & $2 \times \mathrm{T} 15$ \\
\hline & 4 & B30-214-1T-30 & & & $1 \times \mathrm{T} 30$ \\
\hline \multirow{5}{*}{ C50/60 } & 5 & B60-214-A & \multirow{5}{*}{$2 \times 14$} & \multirow{5}{*}{60} & - \\
\hline & 6 & B60-214-1T-15 & & & $1 \times \mathrm{T} 15$ \\
\hline & 7 & B60-214-2T-15 & & & $2 \times \mathrm{T} 15$ \\
\hline & 8 & B60-214-1T-30 & & & $1 \times \mathrm{T} 30$ \\
\hline & 9 & B60-214-2T-30 & & & $2 \times \mathrm{T} 30$ \\
\hline
\end{tabular}

\subsection{Material Properties}

Two concrete mixtures were used for the two series: C35/45 and C50/60. The concrete compressive strength $\left(f_{\mathrm{ccm}, \mathrm{cyl}}\right)$, tensile strength $\left(f_{\mathrm{ctm}, \mathrm{cube}}\right)$, and modulus of elasticity $\left(E_{\mathrm{cm}}\right)$ were evaluated using standard $150 \mathrm{~mm}$ diameter cylinders and standard $150 \mathrm{~mm}$ cubes according to EN 206-1. Strength characteristics of the concrete are summarized in Table 2.

All internal steel reinforcement was class B500B class; the tensile properties were obtained from uniaxial tensile tests performed according to EN 10002. The maximum and minimum yielding stress $\left(f_{\mathrm{sy}, \mathrm{u}}\right.$ and $\left.f_{\mathrm{sy}, 1}\right)$ and maximum tensile stress $\left(f_{\mathrm{su}}\right)$ are summarized in Table 3.

The material characteristics of the CFRP profiles were found using uniaxial tensile tests on $15 \mathrm{~mm} \times 4 \mathrm{~mm} \times 350 \mathrm{~mm}$ specimens cut from the T30 profile web according to ASTM D3039. Based on tensile tests on five such specimens the following properties were determined: the mean tensile strength, $f_{\mathrm{fu}, \mathrm{m}}=1673 \mathrm{MPa}$, the mean moduls of elasticity, $E_{\mathrm{f}, \mathrm{m}}=149 \mathrm{GPa}$ and the mean ultimate strain, $\varepsilon_{\mathrm{fu}, \mathrm{m}}=1.08 \%$. The two-part epoxy adhesive used to bond the CFRP profiles to the concrete surface had an average tensile strength determined according to ISO 527-1-2 equal to $f_{\text {at }}=17.0 \mathrm{MPa}$ and an average compressive strength determined according to PN-EN 196-1 equal to $f_{\text {ca }}=58.0 \mathrm{MPa}$. 
Table 2. The strength characteristics of the concrete.

\begin{tabular}{|c|c|c|c|c|c|c|}
\hline \multirow{4}{*}{ Concrete class } & \multirow{4}{*}{ No. } & \multirow{4}{*}{ Symbol } & \multicolumn{3}{|c|}{ Concrete strength } & \multirow{4}{*}{$\begin{array}{c}\text { Elasticity modulus } \\
E_{\mathrm{cm}} \\
(\mathrm{GPa})\end{array}$} \\
\hline & & & \multicolumn{2}{|c|}{ Compressive } & \multirow{3}{*}{$\begin{array}{c}\text { Tensile } \\
f_{\text {ctm,cube }}\end{array}$} & \\
\hline & & & $f_{\text {ccm,cube }}$ & $f_{\mathrm{ccm}, \mathrm{cyl}}$ & & \\
\hline & & & & (MPa) & & \\
\hline \multirow{4}{*}{ C30/37 } & 1 & B30-214-A & 41.5 & 34.9 & 3.5 & 28.9 \\
\hline & 2 & B30-214-1T-15 & - & 36.5 & - & 26.1 \\
\hline & 3 & B30-214-2T-15 & 41.4 & 34.8 & 3.5 & 28.7 \\
\hline & 4 & B30-214-1T-30 & 42.8 & 36.0 & 3.7 & 28.9 \\
\hline \multirow{5}{*}{ C50/60 } & 5 & B60-214-A & 58.0 & 50.0 & 4.0 & 34.1 \\
\hline & 6 & B60-214-1T-15 & 58.0 & 50.0 & 4.0 & 34.1 \\
\hline & 7 & B60-214-2T-15 & 59.0 & 51.0 & 4.0 & 34.3 \\
\hline & 8 & B60-214-1T-30 & 62.9 & 45.4 & 4.4 & 35.7 \\
\hline & 9 & B60-214-2T-30 & 62.8 & 45.4 & 4.0 & 34.4 \\
\hline
\end{tabular}

Table 3. Strength characteristics of steel reinforcement.

\begin{tabular}{|c|c|c|c|c|c|c|}
\hline \multirow{2}{*}{ Steel bar } & \multicolumn{2}{|c|}{ Yielding strength } & \multirow{2}{*}{$\frac{\text { Yielding strain }}{\varepsilon_{\text {sy }}}$} & \multirow{2}{*}{$\begin{array}{c}\text { Tensile strength } \\
f_{\text {su }}\end{array}$} & \multirow{2}{*}{$\begin{array}{c}\text { Ultimate strain } \\
\varepsilon_{\mathrm{su}}\end{array}$} & \multirow{2}{*}{$\begin{array}{c}\text { Young modulus } \\
E_{\mathrm{s}}\end{array}$} \\
\hline & Upper $f_{\mathrm{sy}, \mathrm{u}}$ & Lower $f_{\text {sy, } 1}$ & & & & \\
\hline$(\mathrm{mm})$ & \multicolumn{2}{|c|}{ (MPa) } & $(\%)$ & $(\%)$ & $(\%)$ & (GPa) \\
\hline 8 & 558.9 & 548.9 & 2.5 & 622.4 & 14.2 & 219.5 \\
\hline 12 & 589.2 & 576.7 & 2.8 & 668.5 & 9.3 & 207.7 \\
\hline 14 & 550.1 & 523.3 & 2.5 & 634.5 & 15.4 & 209.0 \\
\hline
\end{tabular}

\subsection{Strengthening Procedure}

The strengthening technique consisted of the following steps:

- Cutting of $8 \mathrm{~mm}$ wide slots either 18 or $33 \mathrm{~mm}$ deep to accommodate the 15 and $30 \mathrm{~mm}$ T-shaped profiles, respectively (Figure 3a). The application of the $30 \mathrm{~mm}$ profiles required the steel stirrups to be cut through along the entire length of the profile (Figure $2 b$ ).

- Cleaning slots of laitance by compressed air;

- Surface preparation of the CFRP shapes by cleaning with the acetone;

- Preparation of the epoxy adhesive according to the manufacturer recommendations and filling the slots with the epoxy adhesive (Figure 3b);

- Application of the epoxy adhesive on the flange of the T shaped CFRP profile (Figure 3b);

- Introducing the profile's web into the slots and bonding of the profile's flange on the bottom surface of the beams;

- Removing the excess epoxy adhesive (Figure 3c);

The adhesive is allowed to cure at least seven days in a laboratory environment at a temperature of about $20^{\circ} \mathrm{C}$ and relative humidity of about 50 percent.

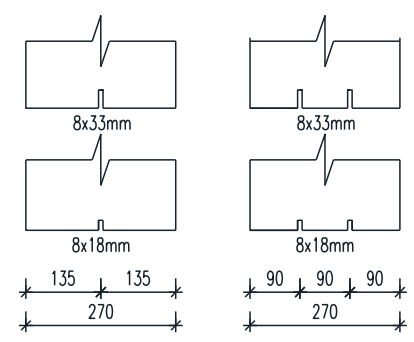

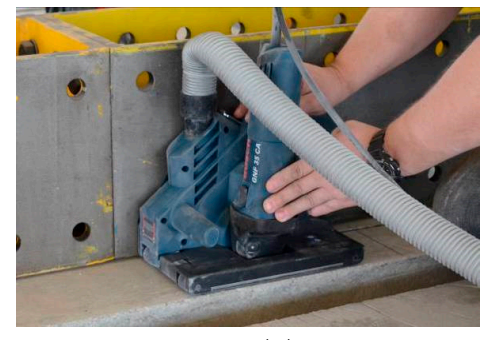

(a)

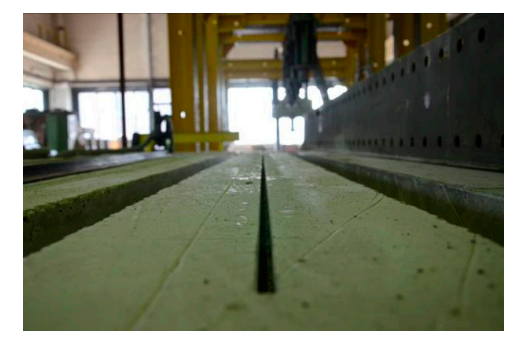

Figure 3. Cont. 

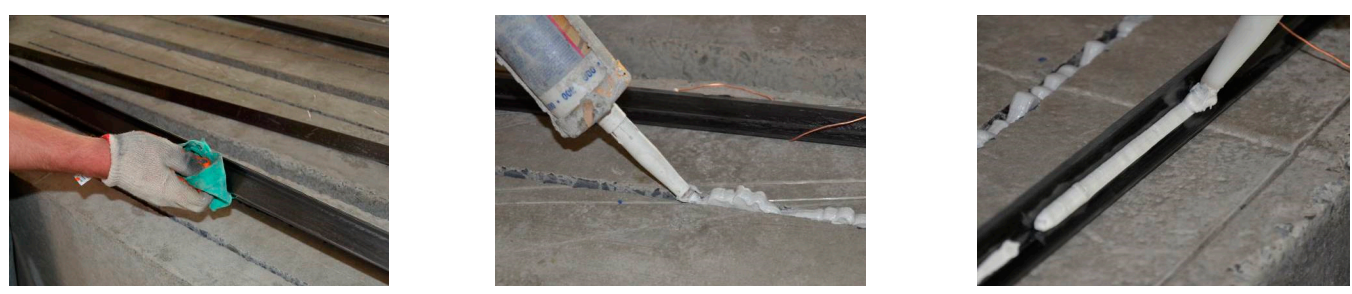

(b)
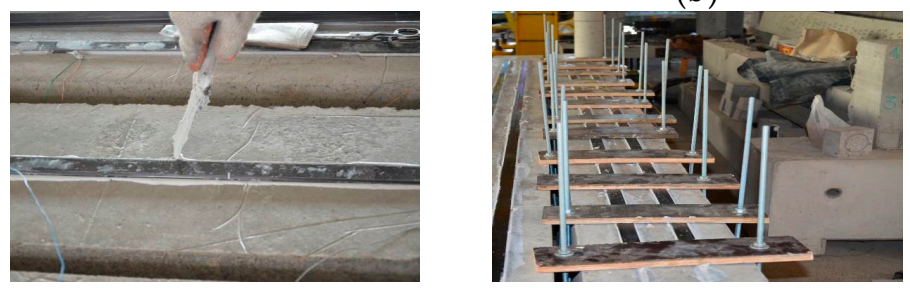

(c)

Figure 3. Strengthening procedure: (a) dimensions of the grooves and cutting procedure;

(b) preparing the profile surfaces and gluing; (c) removing the epoxy and curing.

\subsection{Test Configuration and Instrumentation}

A six point loading scheme with two different loading rates of $0.7 \mathrm{kN} / \mathrm{min}$ (two outermost loads) and $1.0 \mathrm{kN} / \mathrm{min}$ (two innermost loads, see Figure 1) was chosen to simulate a bending moment envelope similar to that of a uniformly distributed load. The tests were carried out in load control, using four servo-hydraulic actuators.

Vertical deflections were measured using nine vertically-oriented $50 \mathrm{~mm}$-stroke LVDTs $\left(\mathrm{V}_{1}-\mathrm{V}_{9}\right)$, placed along the span of the beam, as shown in Figure 4a. Concrete strain at the level of the longitudinal steel reinforcement was measured using five $10 \mathrm{~mm}$ LVDTs placed in compression $\left(R_{c 1}-R_{c 5}\right)$ and eleven 20 mm LVDTs tension $\left(R_{t 1}-R_{t 11}\right)$. Strains in the CFRP profiles were recorded using seven electrical resistance strain gauges $\left(T_{1 p}-T_{7 p}\right)$ placed along the flange of each profile (see Figure $4 \mathrm{~b})$. Two additional strain gauges $\left(\mathrm{T}_{\mathrm{sr} 1}-\mathrm{T}_{\mathrm{sr} 2}\right)$ were applied on the web of the CFRP profile (Figure 4c).

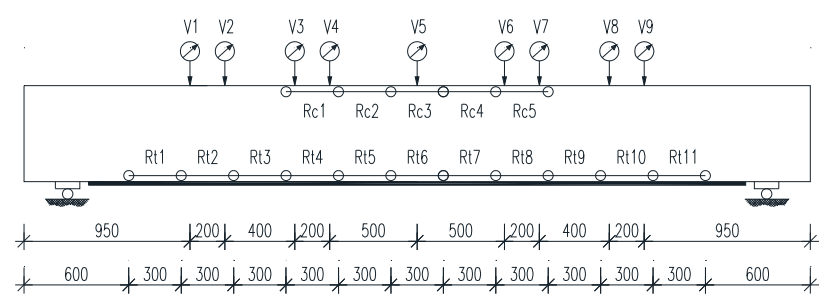

(a)

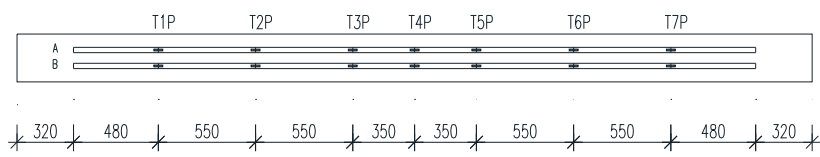

(b)

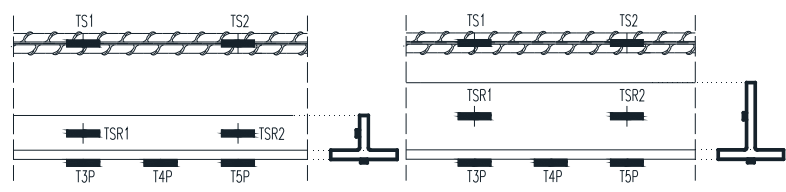

(c)

Figure 4. Measuring devices: (a) LVDTs $\left(\mathrm{V}_{1}-\mathrm{V}_{9}\right)$; (b) strain gauges located on the flange of the CFRP profile $\left(\mathrm{T}_{1 \mathrm{p}}-\mathrm{T}_{7 \mathrm{p}}\right)$; (c) strain gauges on the CFRP profiles $\mathrm{T} 15$ and $\mathrm{T} 30\left(\mathrm{~T}_{\mathrm{sr} 1}, \mathrm{~T}_{\mathrm{sr} 2}\right)$ (all dimensions in $\mathrm{mm}$ ). 


\section{Results and Discussion}

\subsection{Failure Modes}

Reference beams (B30-214-A and B60-214-A) failed in a ductile flexural mode typical of under-reinforced steel-RC structures. The failure featured yielding of the tensile steel reinforcement (SY), which is seen as a progressive increase in the mid-span deflection and a small increase in the applied load, which is discussed in Section 3.3. After the steel yielding and progressive increase in midspan deflection of beam B60-214-A, the applied load was stopped when the mid-span LVDT exceeded its range of $50 \mathrm{~mm}$. In order to obtain higher deflections in beam B30-214-A, a longer $200 \mathrm{~mm}$ LVDT was used. When the midspan deflection reached $104 \mathrm{~mm}$, the concrete in compression, close to the internal loading point started crushing (see Figure 5a) and the beam was immediately unloaded (see Section 3.3). It is worth noting, that these crucial points in the reference beam tests were identified as the ultimate loads and corresponding maximum mid-span deflections. It is expected that the $\mathrm{B} 60$ beam would have continued to a maximum deflection only slightly less than the B30 beam.

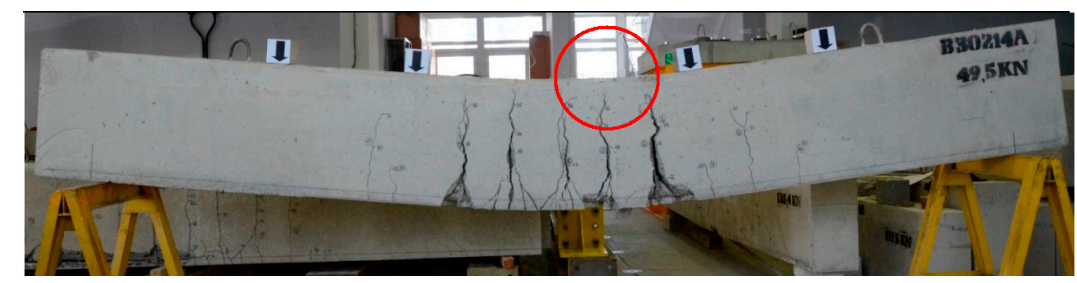

(a)

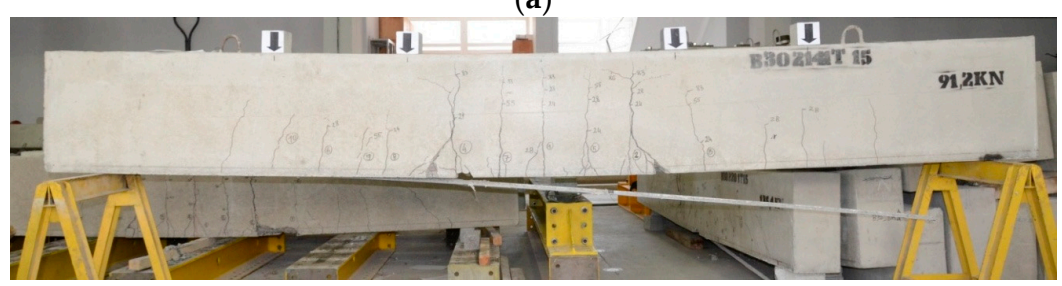

(b)

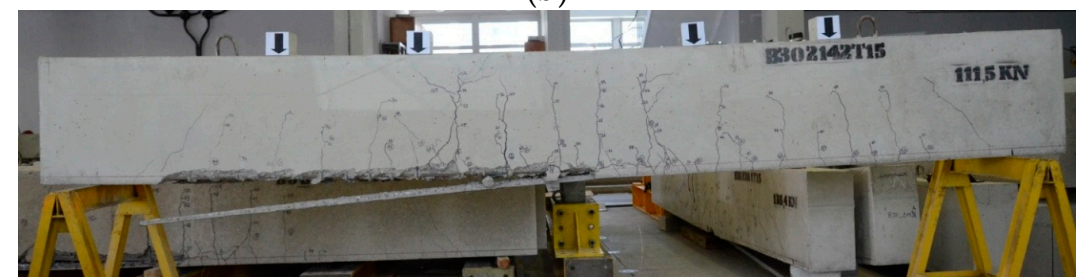

(c)

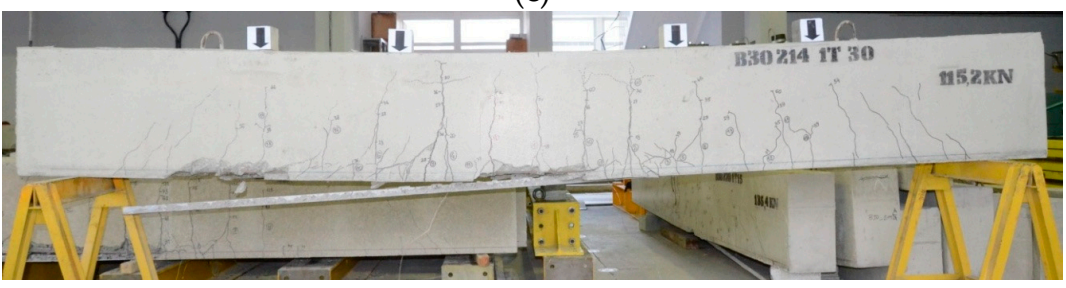

(d)

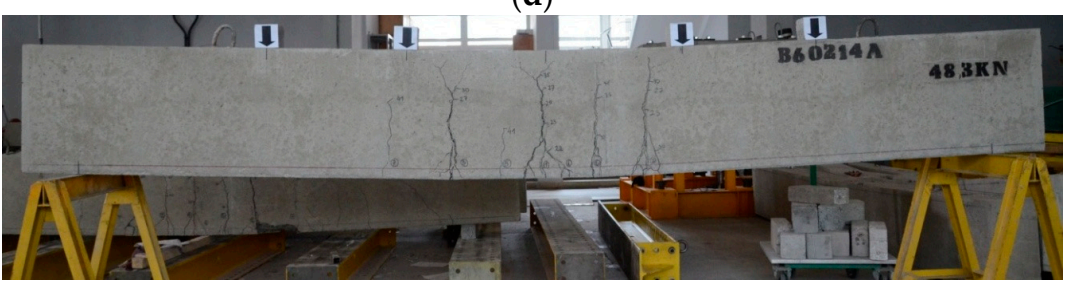

(e)

Figure 5. Cont. 


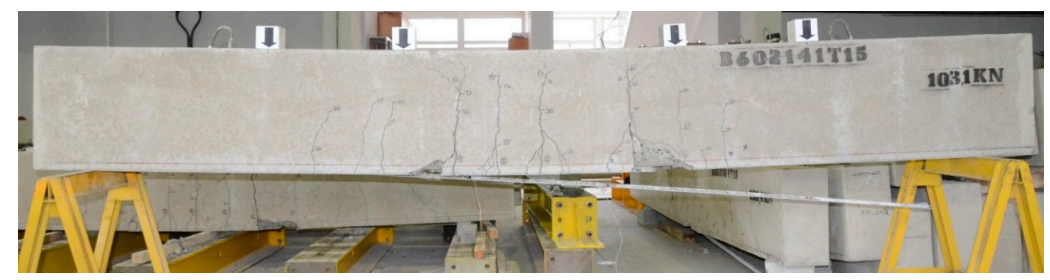

(f)

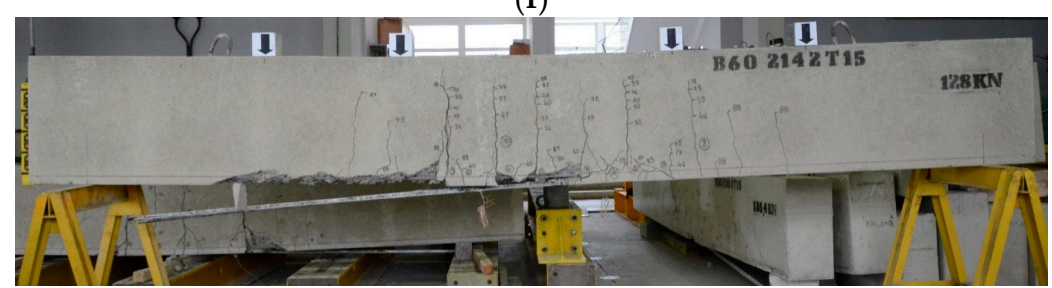

(g)

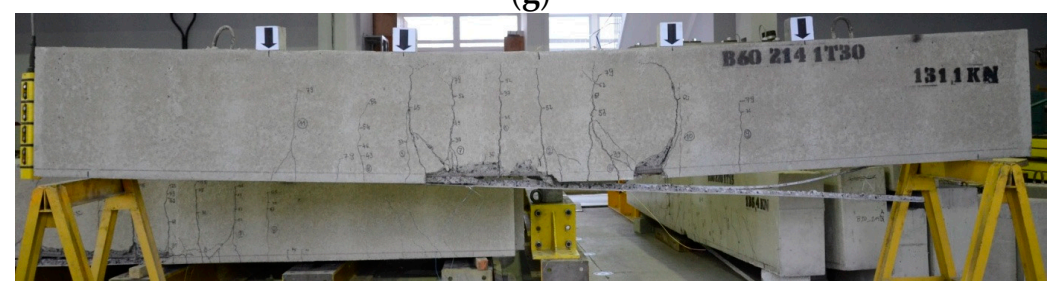

(h)

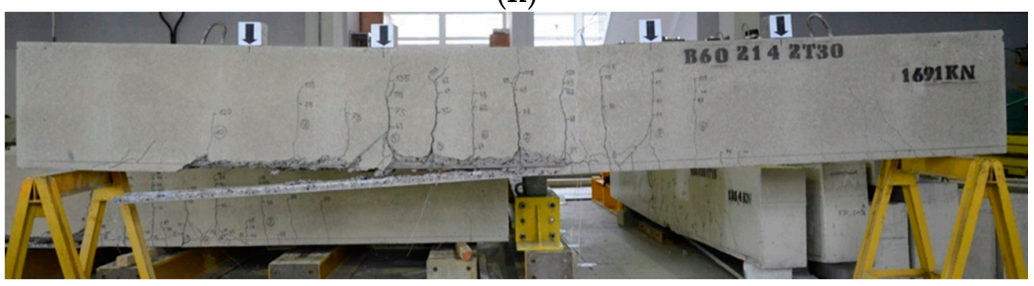

(i)

Figure 5. Failure modes of tested beams: (a-i) corresponding to beams No. (1-9, Table 1).

The strengthened beams failed in almost all cases by intermediate crack debonding (ICD) of the CFRP profiles with adjacent concrete cover splitting (CCS) (Figure 5c-i). This failure initiated in the concrete cover, starting next to the flexural crack closest to the innermost load (i.e., the crack at which the shear-to-moment ratio is greatest). As the width of this crack increased, the crack changed inclination toward the horizontal. Failure occurred as an abrupt debonding from near midspan toward one support of the CFRP profile with attached concrete cover separation (CCS) at the level of the longitudinal steel reinforcement. Failure modes observed in all tested beams are summarized in Table 4 and Figure 5.

One of the strengthened beams (B60-214-1T-15) partially failed by intermediate crack debonding (ICD) and pure interfacial bond failure between the CFRP profile and adhesive (BPA). This failure was caused by a poor adhesion between the smooth CFRP profile and adhesive. In the beams strengthened with the $15 \mathrm{~mm}$ deep profiles, a detached concrete cover consisted of a concrete triangular prism with the CFRP profile inside (see Figure 6).

In two beams strengthened with $30 \mathrm{~mm}$ deep profiles (B60-214-1T-30 and B60-214-2T-30), the ICD failure of the CFRP profile occurred with the partial longitudinal crack separation of the CFRP profiles along the fiber interface being observed (Figure 7). Longitudinal fracture (LFP) of the profile's web occurred after failure of the beams and was caused by the large deflections of the beams and the high interlaminar shear stress developed in the web of the CFRP profile (Figure 7).

The number of profiles (one or two) and their depth had a significant effect on the eventual damaged region of the concrete cover; this was wider in the beams strengthened with two CFRP profiles than in the beams with only one and also wider for a greater web depth (Figure 7). 
The installation of the $30 \mathrm{~mm}$ deep CFRP profiles required cutting of all stirrups along the beam. This did not have any significant impact on the behavior of the strengthened RC members or on the ultimate loads, confirming the observations of $[14,22,23]$.

Table 4. Failure modes of the beams.

\begin{tabular}{cccc}
\hline Series & Figure 5 & Symbol & Failure modes \\
\hline \multirow{5}{*}{ C30/37 } & a & B30-214-A & SY + CC \\
& b & B30-214-1T-15 & ICD + CCS \\
& c & B30-214-2T-15 & ICD + CCS \\
& d & B30-214-1T-30 & ICD + CCS \\
\hline & e & B60-214-A & SY + CC \\
C50/60 & f & B60-214-1T-15 & ICD + BPA \\
& g & B60-214-2T-15 & ICD + CCS \\
& h & B60-214-1T-30 & ICD + LFP \\
& i & B60-214-2T-30 & ICD + LFP \\
\hline
\end{tabular}

SY-steel yielding, CC-concrete crushing, ICD—intermediate crack debonding, CCS—concrete cover splitting, BPA-failure of bond in profile-adhesive interface, LCFP-longitudinal composite fracture of the profile.

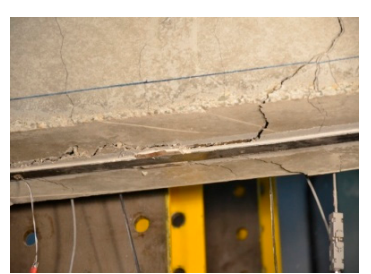

(a)

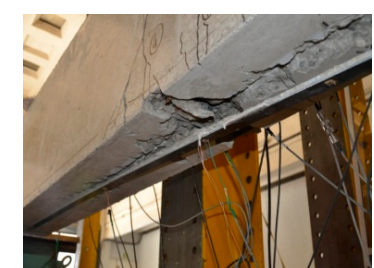

(b)

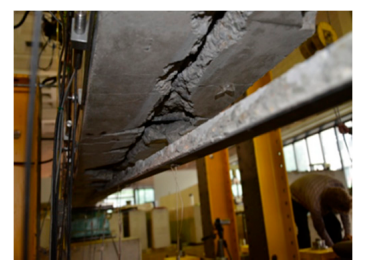

(c)

Figure 6. Failure modes: (a) BPA; (b) ICD and (c) BPA.

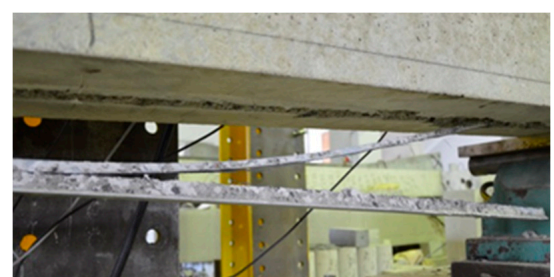

(a)

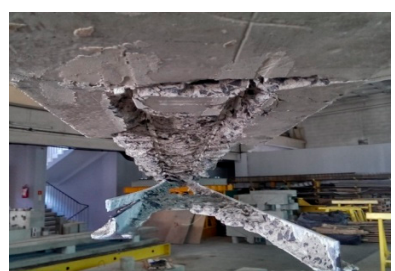

(b)

Figure 7. Longitudinal fracture of the CFRP profile web in beams: (a) B60-214-1T-30; (b) B60-214-2T-30.

Application of the $30 \mathrm{~mm}$ deep profiles led to separation of a large amount of concrete cover (CCS), completely exposing the tensile and shear reinforcement (Figure 8).

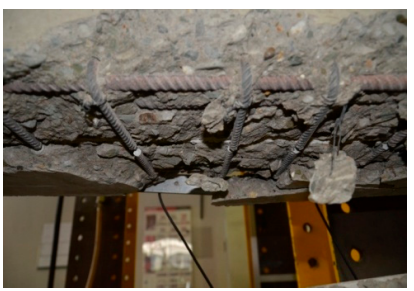

(a)

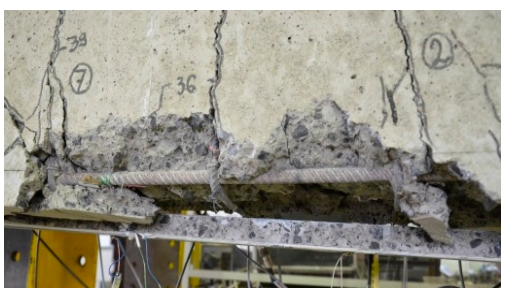

(b)

Figure 8. Separation of a large concrete cover in beam B60-214-1T-30 strengthened with $30 \mathrm{~mm}$ deep profile: (a) bottom side of beam with cut stirrups after T profile separation; (b) debonding of profile with concrete cover separation. 


\subsection{Beam Load Carrying Capacity}

The load values in Table 5 the sum of the applied loads from all four actuators (i.e., $2 \times 1 F+2 \times 0.7 F=3.4 F)$. The midspan moment is therefore 0.58 times the total load reported $(\mathrm{kN}-\mathrm{m})$ and the maximum shear is 0.5 times the total load reported $(\mathrm{kN})$. The applied load corresponding to concrete cracking $\left(3.4 F_{\mathrm{cr}}\right.$, column 3$)$, steel yielding $\left(3.4 F_{\mathrm{sy}}\right.$, column 5$)$ and the ultimate load $\left(3.4 F_{\mathrm{u}}\right.$, column 7$)$, and their corresponding deflections $(\Delta$, columns $4,6,8)$ are shown in Table 5 . The cracking load refers to the load at which the first flexural crack occurred. The yielding load corresponds to the load, at which the strain gauges mounted on the tensile steel reinforcement recorded strain corresponding to the steel yielding (see Table 3).

Table 5. Results of the experimental program.

\begin{tabular}{|c|c|c|c|c|c|c|c|c|c|c|c|}
\hline 1 & 2 & 3 & 4 & 5 & 6 & 7 & 8 & 9 & 10 & 11 & 12 \\
\hline No. & Symbol & $\begin{array}{c}3.4 F_{\mathrm{cr}} \\
(\mathrm{kN})\end{array}$ & $\begin{array}{c}\Delta_{\mathrm{cr}} \\
(\mathrm{mm})\end{array}$ & $\begin{array}{c}3.4 F_{\mathrm{y}} \\
(\mathrm{kN})\end{array}$ & $\begin{array}{c}\Delta_{\mathrm{y}} \\
(\mathrm{mm})\end{array}$ & $\begin{array}{c}3.4 F_{\mathrm{u}} \\
(\mathrm{kN})\end{array}$ & $\begin{array}{c}\Delta_{\mathbf{u}} \\
(\mathrm{mm})\end{array}$ & $\begin{array}{c}\eta_{f} \\
(\%)\end{array}$ & $\begin{array}{c}\mathcal{E}_{\text {f.flange }} \\
(\%)\end{array}$ & $\begin{array}{c}\varepsilon_{\text {f.web }} \\
\text { (\%) }\end{array}$ & $\begin{array}{c}\eta_{\varepsilon} \\
(\%)\end{array}$ \\
\hline 1 & B30-214-A & 61.2 & 1.8 & 119 & 6.8 & 166.6 & 103.5 & - & - & - & - \\
\hline 2 & B30-214-1T-15 & 81.6 & 2.5 & 186.6 & 9.4 & 309.4 & 29.4 & 85.7 & 0.73 & 0.75 & 69.0 \\
\hline 3 & B30-214-2T-15 & 61.2 & 1.2 & 255 & 6.8 & 380.8 & 25.9 & 128.6 & 0.52 & 0.55 & 48.0 \\
\hline 4 & В30-214-1T-30 & 68.0 & 1.4 & 221.3 & 10.8 & 391.0 & 40.1 & 134.7 & 0.77 & $x$ & 71.0 \\
\hline 5 & B60-214-A & 78.2 & 0.7 & 136 & 6.6 & 163.2 & 61.7 & - & - & - & - \\
\hline 6 & B60-214-1T-15 & 102 & 1.5 & 204 & 8.3 & 350.2 & 36.2 & 114.6 & 0.78 & 0.80 & 74.0 \\
\hline 7 & B60-214-2T-15 & 108.8 & 1.5 & 272 & 9.3 & 435.2 & 25.2 & 166.7 & 0.61 & 0.67 & 62.0 \\
\hline 8 & B60-214-1T-30 & 105.4 & 1.4 & 221 & 7.6 & 445.4 & 44.4 & 172.9 & 0.92 & 0.89 & 85.0 \\
\hline 9 & B60-214-2T-30 & 105.4 & 1.1 & 316.2 & 10.7 & 574.6 & 32.4 & 252.1 & 0.69 & 0.69 & 64.0 \\
\hline
\end{tabular}

A measure of strengthening efficiency is the strengthening ratio calculated as:

$$
\eta_{f}=\frac{F_{u}-F_{0}}{F_{0}} \cdot 100 \%
$$

where $F_{u}$ and $F_{0}$ are the ultimate load of the strengthened and unstrengthened reference beam, respectively.

In terms of the ultimate load, the strengthening efficiency ranged from $85.7 \%$ (beam B30-214-1T-15) to 252.1\% (for the beam B60-214-2T30). A similar or marginally greater strengthening effect was achieved for the beams strengthened with one T30 profile $\left(\eta_{f}=134.7 \%\right.$ and $172.9 \%$ for B30 and B60, respectively) over those with two T15 profiles ( $\eta_{\mathrm{f}}=128.6 \%$ and $\left.166.7 \%\right)$. It is also seen from these results that the efficiency of the strengthening was improved for the higher strength concrete beams. This is to be expected for these initially under-reinforced sections: the greater reinforcement permits a greater concrete component to be engaged in resisting moment.

As expected, the greatest strengthening effect was obtained for beam B60-214-2T30, strengthened with two CFRP $30 \mathrm{~mm}$ deep profiles, showing a 29\% increase in capacity over beam B60-214-1T30 strengthened with only one $30 \mathrm{~mm}$ profile.

The maximum strains in the CFRP profile flange $\left(\varepsilon_{\text {f.flange, }}\right.$ column 10$)$ and in the CFRP web $\left(\varepsilon_{\text {f.web }}\right.$, column 11$)$ of the profile are reported in Table 5 . The strain efficiency $\left(\eta_{\varepsilon}\right.$, column 12$)$, is the ratio of the maximal CFRP tensile strain $\varepsilon_{\text {f.max }}$ to the experimentally determined ultimate strain of $\varepsilon_{\mathrm{fu}}=1.08 \%$ :

$$
\eta_{\varepsilon}=\frac{\varepsilon_{f \max }}{\varepsilon_{f u}} \cdot 100 \%
$$

The test results indicated the influence of the concrete strength on the strengthening efficiency. Strengthening of the C50/60 beams indicated an increase in the cracking load $\left(F_{\mathrm{cr}}\right)$ of $30.4 \%$ to $39.1 \%$ for the $\mathrm{B} 60$ series and $0 \%$ to $33 \%$ for the $\mathrm{B} 30$ series. While the concrete strength affected an increase in the ultimate load of $11.6 \%$ for the beam strengthened with one $15 \mathrm{~mm}$ profile (compare 
beams B30-214-1T-15 and B60-214-1T-15), more than 14.3\% for the beams strengthened with two $15 \mathrm{~mm}$ profiles (B30-214-2T-15 and B60-214-2T-15) and 13.9\% for beams with one $30 \mathrm{~mm}$ profile (B30-214-1T-30 and B60-214-1T-30).

The typical limit state for EBR and NSM strengthening is FRP-to-concrete bond conditions with NSM attributing greater bond performance. Based on existing studies on bond behavior of the NSM FRP-to-concrete $[8,9,17]$, the recommended value of the design FRP strain in NSM technique is $\varepsilon_{\mathrm{fd}}=0.7 \varepsilon_{\mathrm{fu}}$. The maximum strain of the $15 \mathrm{~mm}$ profiles reach an average strain of $\varepsilon_{\text {f.max }}=0.78 \varepsilon_{\text {f.u }}$. The cross section area of the $15 \mathrm{~mm}$ T-profile is about 4.4 times greater than a conventional $(15 \mathrm{~mm} \times 2.5 \mathrm{~mm}) \mathrm{NSM}$ embedded strip therefore requiring only about one quarter of the installation time, labor, and cost to achieve the same strengthening effect. Similarly, by comparison to the EB technique, where intermediate crack debonding may limit efficiency to the order of $\varepsilon_{\text {f.max }}=0.35 \varepsilon_{\text {f.u }}$, the use of the $15 \mathrm{~mm}$ deep T-profile is almost twice as efficient, requiring only one half of the material. Like the T-profile, most procured CFRP strips for EB or NSM application are pultruded, thus the cost difference between the profile and strip is based mostly on the amount of material, since manufacturing complexity is essentially the same.

\subsection{Force-Deflection Relationships}

Comparison of the load-deflection curves for the reference and strengthened beams in terms of the CFRP profile height, the number of profiles, and concrete strength are shown in Figures 9 and 10 respectively. The test results confirm the opinion $[17,26]$ on the influence of the CFRP ratio $\left(\rho_{f}\right)$ and CFRP stiffness $\left(E_{\mathrm{f}} I_{\mathrm{f}}\right)$ on strengthened beam ductility. An increase in $\rho_{\mathrm{f}}$ leads to a decrease in the maximal mid-span deflection and renders the strengthened element less ductile.

A comparative analysis of the vertical mid-span displacement depends mainly on the influence of the concrete strength, number of profiles, and their height. The results of all beams confirmed a significant reduction of between $67 \%-83 \%$ and $30 \%-60 \%$, for B30 and B60 series, respectively, in mid-span deflection following strengthening. The concrete strength had an effect on the stiffness of the beams (compare B30-214-1T-15 and B60-214-1T-15), which, as expected, was greater for the beams made of higher concrete strength.

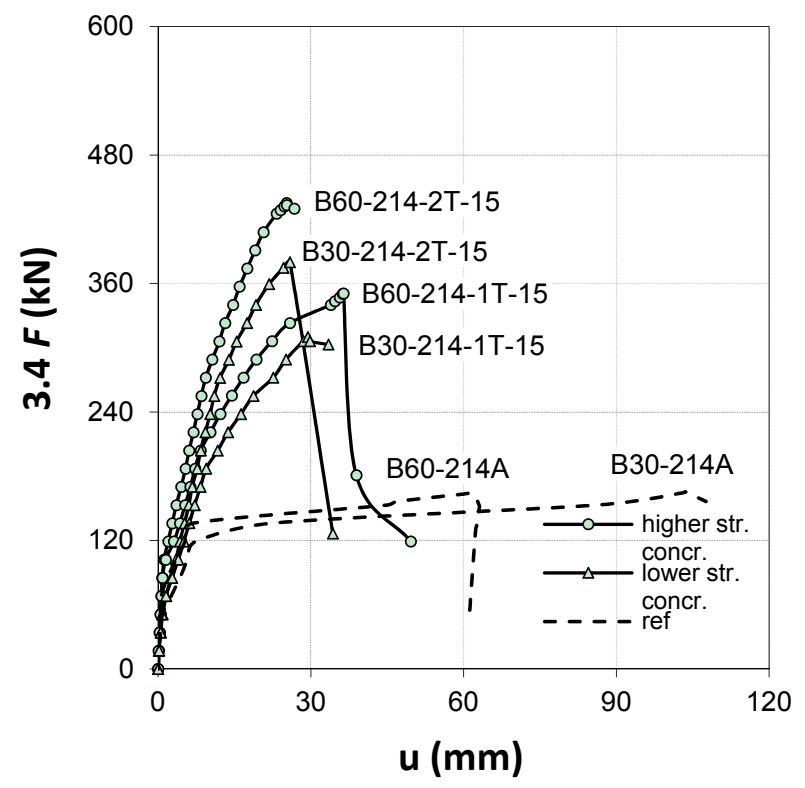

(a)

Figure 9. Cont. 


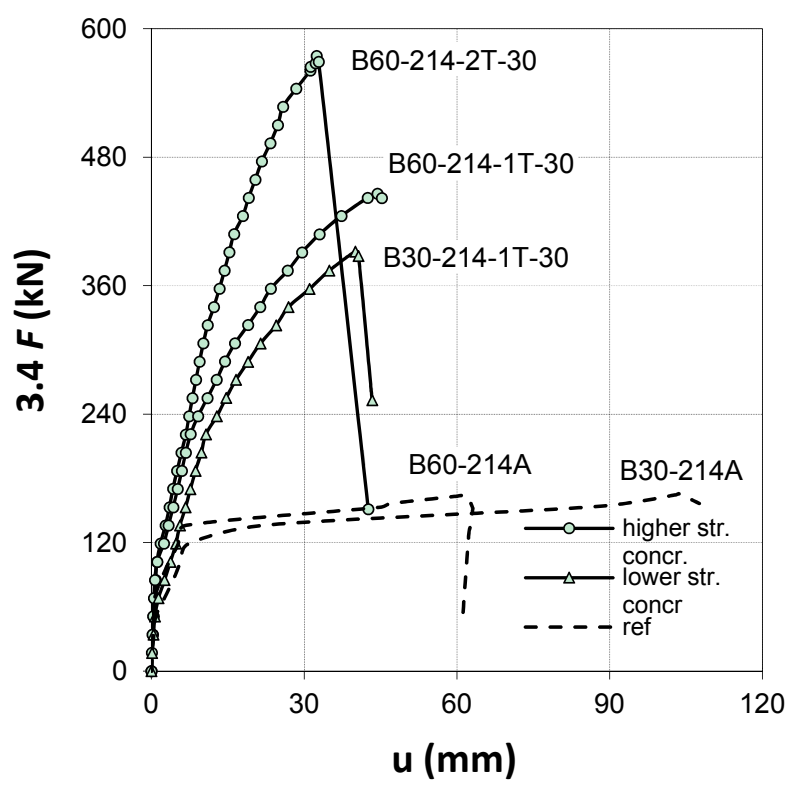

(b)

Figure 9. Total load $v$ s. mid-span deflection relationships in terms of profile web height: (a) T15 and (b) T30.

Comparing mid-span deflection curves of the beams strengthened with 15 and $30 \mathrm{~mm}$ profiles, an insignificant difference in stiffness was observed between concrete cracking and the steel yielding. This difference grows following the internal steel reinforcement yielding, however, but is observed only in the beams strengthened with the single CFRP profile. The beams strengthened with two CFRP profiles indicated a difference in the beam stiffness only following concrete cracking. This observation confirms opinion about the effect of the CFRP ratio $\left(\rho_{\mathrm{f}}\right)[17,26]$ on the concrete cracking initiation.

A detailed summary of midspan deflection through the load history is shown in Table 6. It is confirmed that with an increase in the CFRP reinforcement ratio the maximum deflection decreases. The shaded regions in Table 6 indicate pre-steel yielding loads.

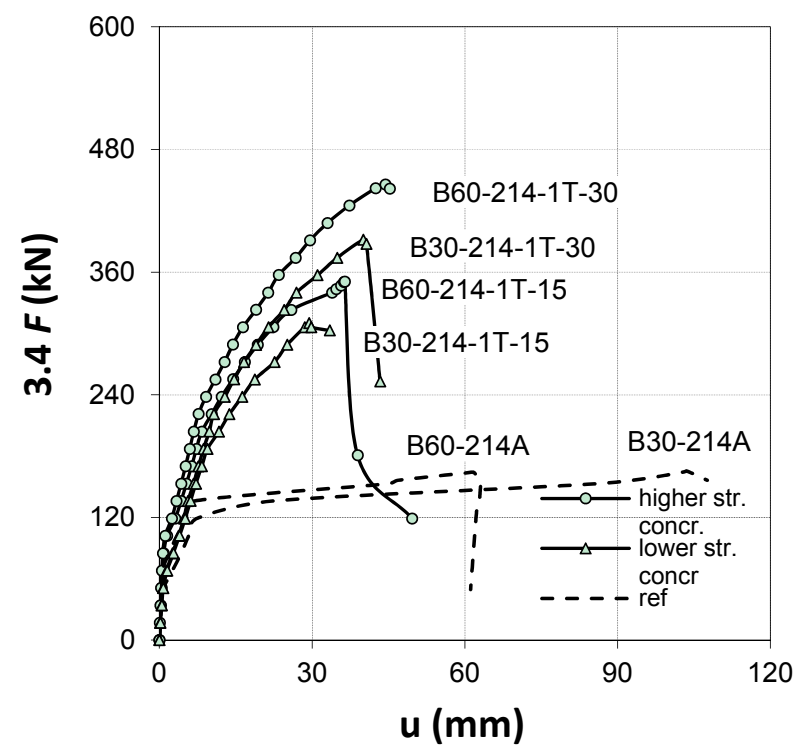

(a)

Figure 10. Cont. 


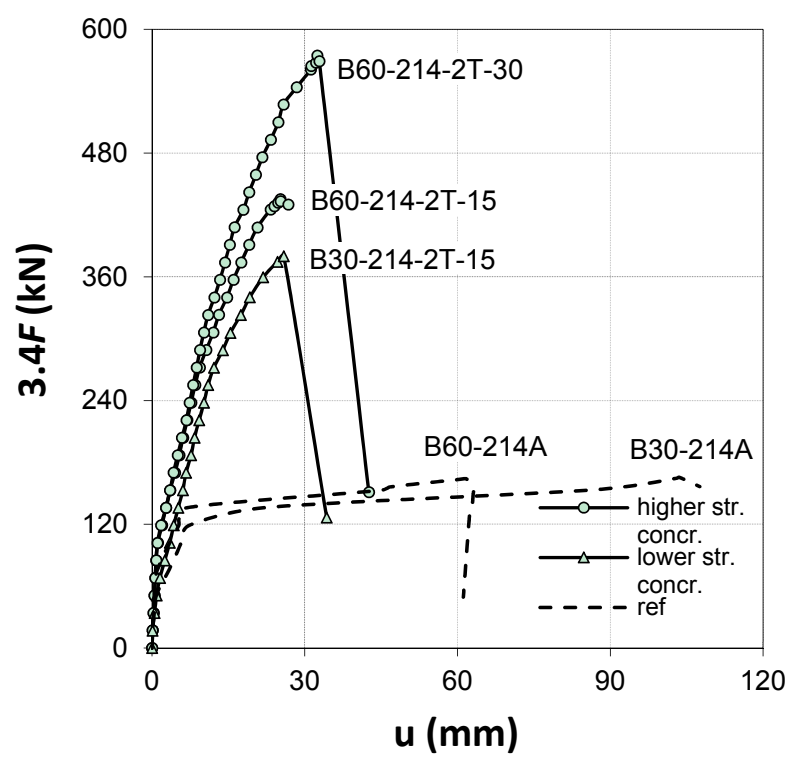

(b)

Figure 10. Total load vs. mid-span deflection relationships in terms of a number of profiles in beams reinforced with profiles: (a) T15 and (b) T30.

Table 6. Mid-span deflection at various total applied load levels.

\begin{tabular}{|c|c|c|c|c|c|c|c|c|c|}
\hline \multirow{2}{*}{ No. } & \multirow{2}{*}{ Symbol } & & \multicolumn{7}{|c|}{$3.4 F$} \\
\hline & & & $85 \mathrm{kN}$ & $119 \mathrm{kN}$ & $170 \mathrm{kN}$ & $225 \mathrm{kN}$ & $340 \mathrm{kN}$ & $425 \mathrm{kN}$ & $510 \mathrm{kN}$ \\
\hline 1 & B30-214-A & & 5.0 & 6.0 & - & - & - & - & - \\
\hline 2 & B30-214-1T-15 & & 3.0 & 5.0 & 8.0 & 19.0 & - & - & - \\
\hline 3 & В30-214-2T-15 & & 3.0 & 4.0 & 6.0 & 11.0 & 19.0 & - & - \\
\hline 4 & В30-214-1T-30 & ultimate & 2.5 & 5.0 & 7.5 & 14.5 & 27.0 & - & - \\
\hline 5 & B60-214-A & deflection at the & 2.0 & 5.0 & - & - & - & - & - \\
\hline 6 & B60-214-1T-15 & load level (mm) & $<1.0^{1}$ & 3.0 & 6.5 & 14.5 & 34.0 & - & - \\
\hline 7 & B60-214-2T-15 & & $<1.0^{1}$ & 2.0 & 4.5 & 8.5 & 14.5 & 23.5 & - \\
\hline 8 & B60-214-1T-30 & & $0.5^{1}$ & 2.5 & 5.0 & 10.0 & 20.0 & 37.5 & - \\
\hline 9 & B60-214-2T-30 & & $<1.0^{1}$ & 1.5 & 4.0 & 8.0 & 12.0 & 18.0 & 25.0 \\
\hline
\end{tabular}

\footnotetext{
${ }^{1}$ pre cracking; shaded entries indicating pre-steel yield.
}

For example, in the reference beam B60-214-A the maximum deflection of $6 \mathrm{~mm}$ was registered under the load of $3.4 F=119 \mathrm{kN}$. While in the corresponding beams strengthened with the CFRP profiles, a significant reduction of deflection was observed for the same loads (see Table 6). The beams B30-214-A, B30-214-1T-15, and B30-214-2T-15 showed under the load of 3.4F $=119 \mathrm{kN}$ the mid-span deflections of $6 \mathrm{~mm}, 5 \mathrm{~mm}$, and $4 \mathrm{~mm}$, respectively. The green fields in Table 6 refer to deflections before steel yielding, while the blank fields present the vertical displacements after steel yielding.

\subsection{Force-Strain Relationship}

Figures 11 and 12 show the strains measured on the web and flange of the CFRP profile (averaged from two characteristic locations: $T_{3 \mathrm{P}}$ and $T_{5 \mathrm{P}}$ on the flange and $T_{\mathrm{SR} 1}$ and $T_{\mathrm{SR} 2}$ on the web). A similar strain distribution and history is seen in each beam.

An increase in the CFRP reinforcing ratio corresponds to a decrease in the maximum CFRP strain observed at failure reflecting a bond-dominated less ductile response. Also shown in Figures 11 and 12 is the average concrete strain measured obtained from two LVDTs (Rt5 and Rt7) placed in the constant moment region at the level of the tensile steel reinforcement. The plots 
confirm initiation and gradual CFRP debonding from the concrete cover for CFRP strain greater than about $0.4 \%)$.
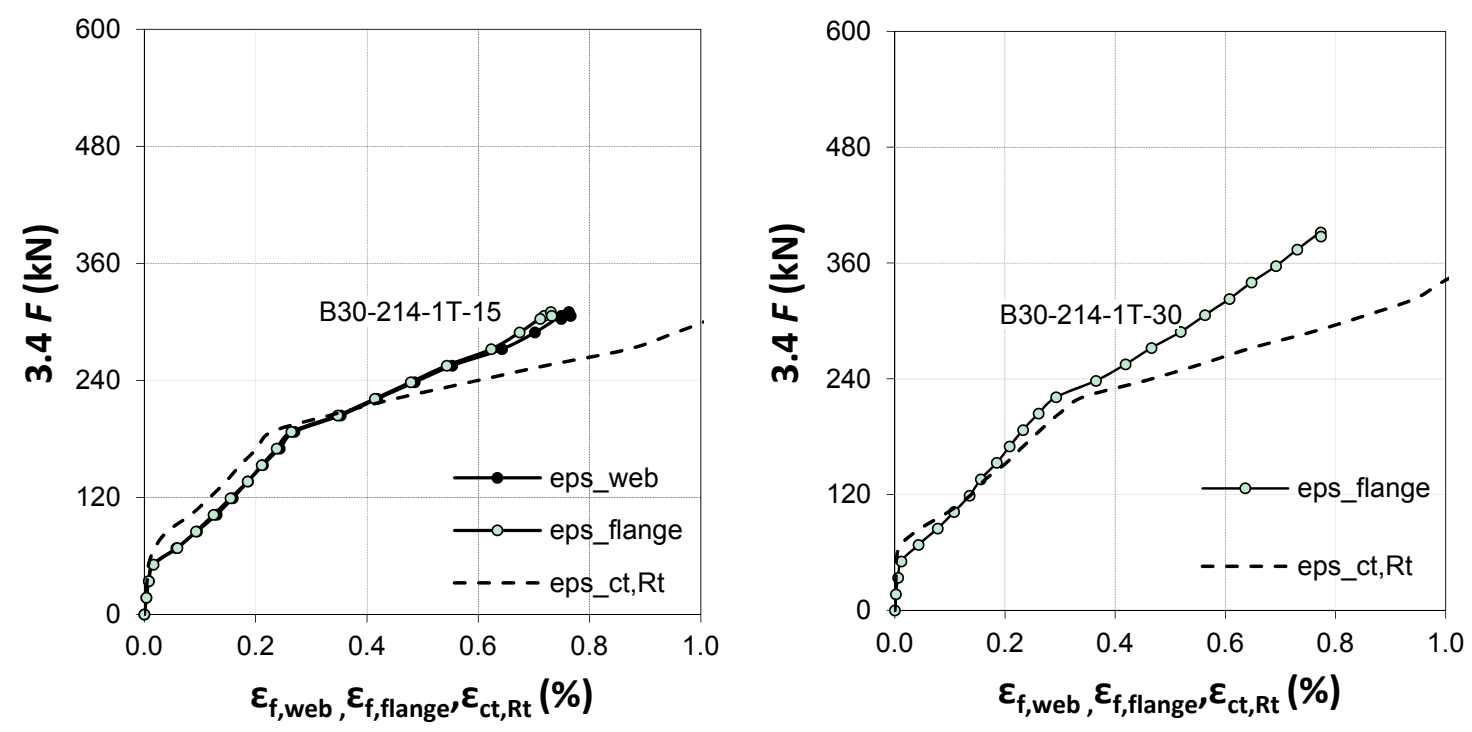

(a)
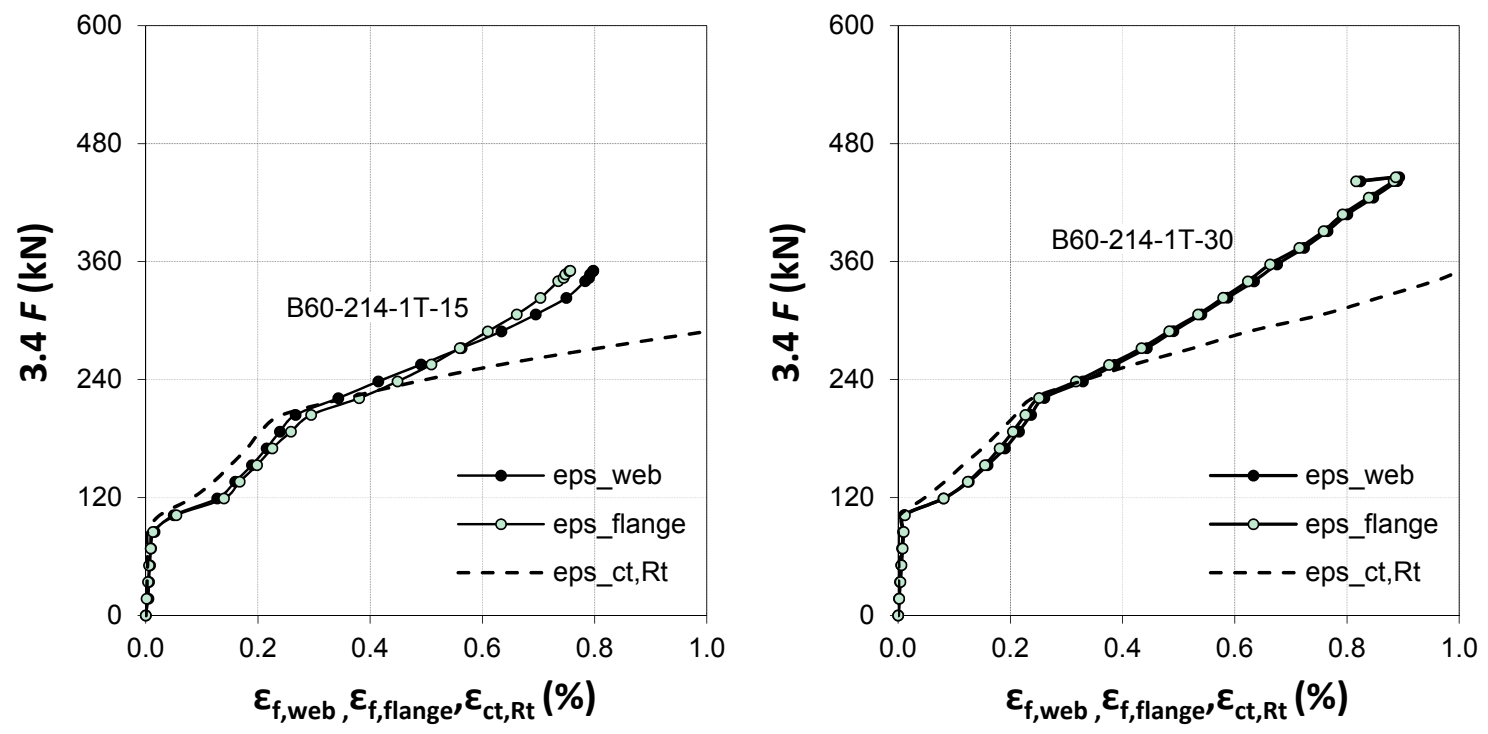

(b)

Figure 11. Total load vs. CFRP strain for the beams strengthened with one CFRP profile: (a) concrete C25/30; (b) concrete C50/60.

The CFRP strain in the beams strengthened with a single T-shaped profile indicated higher values than those strengthened with two profiles. Moreover, a beneficial effect of the concrete strength on the CFRP strain is apparent in Figures 11 and 12. The maximum strain in the $30 \mathrm{~mm}$ profiles was slightly higher than that in the $15 \mathrm{~mm}$ profiles; this likely results from the greater bond area of the $30 \mathrm{~mm}$ profiles. 


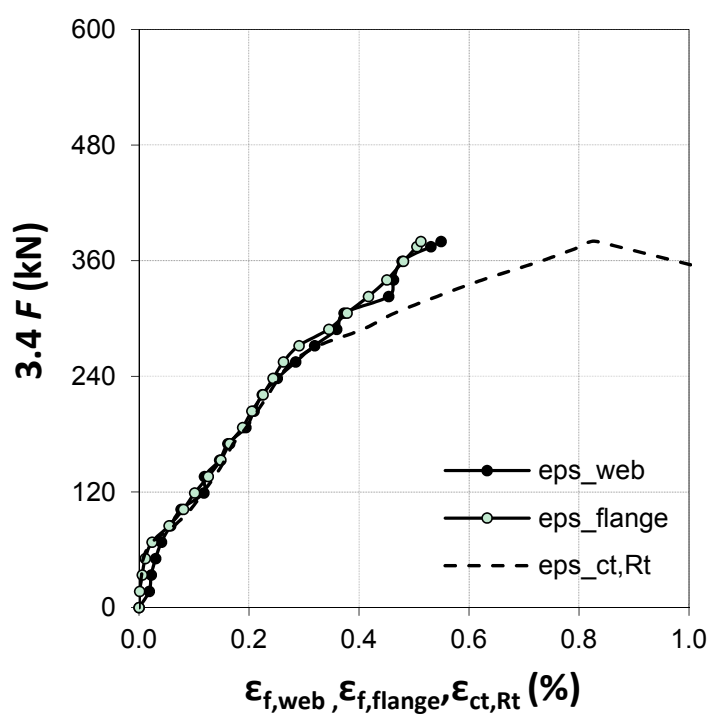

(a)
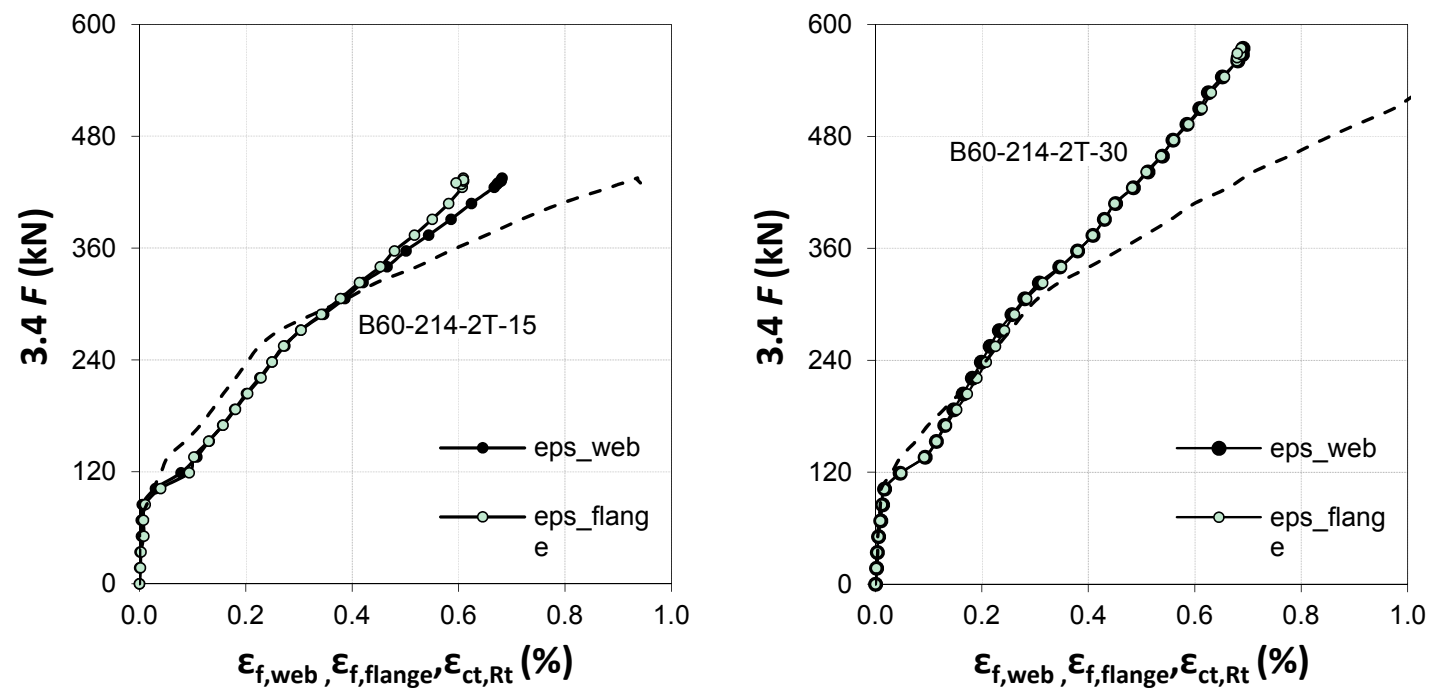

(b)

Figure 12. Total load vs. CFRP strain for the beams strengthened with two CFRP profiles (a) concrete C25/30; (b) concrete C50/60.

\section{Conclusions}

The test results of seven full scale RC beams strengthened with T-shaped CFRP profiles and two non-strengthened reference beams yielded promising results, which encourage using the proposed method in field applications for repair and maintenance of existing RC structures. Flexural strengthening using CFRP T-profiles significantly enhanced flexural capacity of existing RC members. The increase in the ultimate load ranged from $86 \%$ to $250 \%$ in comparison to non-strengthened reference beams. Utilization of the CFRP tensile strength was influenced by the depth (15 and $30 \mathrm{~mm})$ and number (one or two) of CFRP profiles used. The profiles with greater web depth $(30 \mathrm{~mm})$ registered higher strains ranged from $0.7 \%$ to $0.9 \%$, while $15 \mathrm{~mm}$ deep profiles showed CFRP strains from $0.5 \%$ to $0.8 \%$. The increased ratio of bond area to cross sectional area of the $30 \mathrm{~mm}$ profiles provided a greater resistance to concrete cover tensile splitting, due to an improved confinement provided by the concrete surrounding the T-shaped profile. The greater resistance to concrete cover splitting resulted in higher load carrying and deflection capacities of the RC beams strengthened with CFRP profiles. 
Concrete strength was also observed to affect strengthening capacity and CFRP efficiency. In this study, initially under-reinforced beams having C50/60 concrete demonstrated both greater strengthening potential and permitted greater efficiency of the CFRP profile to be engaged.

The increase in the CFRP reinforcement ratio caused an increase in the ultimate load and in beam stiffness, however it reduced the maximum CFRP strain observed in the test. The concrete strength affected the CFRP strain utilization and the ultimate loads. Cutting of the bottom transverse arm of steel stirrups during the NSM profile installation did not affect the ultimate load or the beam deformability, nonetheless, such practice is strongly discouraged and is not permitted in any known design recommendation or standard. It is to be noted that the tested beams were provided with additional (uncut) shear reinforcement in the form of bent-up bars. The test results confirmed the application of the T-shaped CFRP profiles as a promising alternative to existing FRP strengthening systems.

Acknowledgments: The authors would like to acknowledge the company Mostostal Warszawa S.A. for providing the CFRP T-shaped profiles and Lodz University of Technology for co-funding of the research program.

Author Contributions: Szymon Cholostiakow prepared figures and tables and contributed to the writing of the paper. Renata Kotynia coordinated the study, interpreted the results, discussion, and conclusions.

Conflicts of Interest: The authors declare no conflict of interest.

\section{References}

1. Kotynia, R.; Baky, H.A.; Neale, K.W.; Ebead, U.A. Flexural strengthening of RC beams with externally bonded CFRP systems: Test results and 3-D nonlinear FE analysis. J. Compos. Constr. 2008, 12, 190-201. [CrossRef]

2. Bank, L.C.; Borowicz, D.T.; Arora, D.; Lamanna, A.J.; Ray, J.C.; Velazquez, G.I. Strengthening of Concrete Beams with Fasteners and Composite Material Strips—Scaling and Anchorage Issues; Report ERDC/GSL TR-04-5; US Army Corps of Engineers: Washington, DC, USA; p. 154.

3. Del Vecchio, C.; di Ludovico, M.; Balsamo, A.; Prota, A.; Manfredi, G.; Dolce, M. Experimental investigation of exterior RC beam-column joints retrofitted with FRP systems. J. Compos. Constr. 2014, 18, 04014002. [CrossRef]

4. Blaschko, M.; Zilch, K. Rehabilitation of concrete structures with CFRP strips glued into slits. In Proceedings of the 12th International Conference on Composite Materials, Paris, France, 5-9 July 1999.

5. De Lorenzis, L.; Rizzo, A.; la Tegola, A. A modified pull-out test for bond of near surface mounted FRP rods in concrete. Compos. B 2002, 33, 589-603. [CrossRef]

6. Blaschko, M. Bond behaviour of CFRP strips glued into slits. In World Scientific, Proceedings of the 6th International Symposium on FRPRCS, Singapore, 8-10 July 2003; Tan, K.H., Ed.; World Scientific Publishing: Singapore city, Singapore, 2003; pp. 205-214.

7. Taljsten, B.; Carolin, A.; Nordin, H. Concrete structures strengthened with near surface mounted reinforcement of CFRP. Adv. Struct. Eng. 2003, 6, 201-213. [CrossRef]

8. Hassan, T.; Rizkalla, S. Investigation of bond in concrete structures strengthened with near surface mounted carbon fiber reinforced polymer strips. J. Compos. Constr. 2003, 7, 248-257. [CrossRef]

9. De Lorenzis, L.; Lundgren, K.; Rizzo, A. Anchorage length of near-surface mounted fiber-reinforced polymer bars for concrete strengthening-Experimental investigation and numerical modelling. ACI Struct. J. 2004, 101, 269-278.

10. Parretti, R.; Nanni, A. Strengthening of RC members using near-surface mounted FRP composites: Design overview. Adv. Struct. Eng. 2004, 7, 469-483. [CrossRef]

11. De Lorenzis, L. Anchorage length of near-surface mounted fiber reinforced polymer bars for concrete strengthening-Analytical modeling. ACI Struct. J. 2004, 101, 375-386.

12. El-Hacha, R.; Rizkalla, S. Near-surface-mounted fiber-reinforced polymer reinforcements for flexural strengthening of concrete structures. ACI Struct. J. 2004, 101, 717-726.

13. Hassan, T.; Rizkalla, S. Bond mechanism of near-surface-mounted fiber reinforced polymer bars for flexural strengthening of concrete structures. ACI Struct. J. 2004, 101, 830-839. 
14. Seracino, R.; Saifulnaz, R.; Oehlers, D. Generic debonding resistance of EB and NSM plate-to-concrete joints. J. Compos. Constr. 2007, 11, 62-70. [CrossRef]

15. Barros, J.; Fortes, A.S. Flexural strengthening of concrete beams with CFRP laminates bonded into slits. Cem. Concr. Compos. 2005, 27, 471-480. [CrossRef]

16. Barros, J.; Dias, S. Near surface mounted CFRP laminates for shear strengthening of concrete beams. Cem. Concr. Compos. 2006, 28, 276-292. [CrossRef]

17. Kotynia, R. Analysis of reinforced concrete beams strengthened with near surface mounted FRP reinforcement. Arch. Civ. Eng. 2006, 52, 305-317.

18. De Lorenzis, L.; Teng, J.G. Near-surface mounted FRP reinforcement: An emerging technique for strengthening structures. Compos. B 2007, 38, 119-143. [CrossRef]

19. Al-Mahmoud, F.; Castel, A.; François, R.; Tourneur, C. Strengthening of RC members with near-surface mounted CFRP rods. Compos. Struct. 2009, 91, 138-147. [CrossRef]

20. Islam, A. Effective methods of using CFRP bars in shear strengthening of concrete girders. Eng. Struct. 2009, 31, 709-714. [CrossRef]

21. Rasheed, H.; Harrison, R.; Peterman, R.; Alkhrdaji, T. Ductile strengthening using externally bonded and near surface mounted composite systems. Compos. Struct. 2010, 92, 2379-2390. [CrossRef]

22. Barros, A.; Ferreira, D.; Fortes, A.; Dias, S. Assessing the effectiveness of embedding CFRP laminates in the near surface for structural strengthening. Constr. Build. Mater. 2006, 20, 478-491. [CrossRef]

23. Teng, J.; de Lorenzis, L.; Wang, B.; Li, R.; Wong, T.; Lam, L. Debonding failures of RC beams strengthened with near surface mounted CFRP strips. J. Compos. Constr. 2006, 10, 92-105. [CrossRef]

24. Yost, J.; Gross, S.; Dinehart, D.; Mildenberg, J. Flexural behaviour of concrete beams strengthened with near-surface-mounted CFRP strips. ACI Struct. J. 2007, 104, 430-437.

25. Costa, I.G.; Barros, J.A.O. Flexural and shear strengthening of RC beams with composites materials-The influence of cutting steel stirrups to install CFRP strips. Cem. Concr. Compos. 2010, 32, 544-553. [CrossRef]

26. Kotynia, R. Bond between FRP and concrete in reinforced concrete beams strengthened with near surface mounted and externally bonded reinforcement. Constr. Build. Mater. 2012, 32, 41-54. [CrossRef]

27. MacGregor, J.G.; Wight, J.K. Reinforced Concrete Mechanics and Design, 6th ed.; Pearson Education, Inc.: Upper Saddle River, NJ, USA, 2012; p. 1157.

(C) 2015 by the authors; licensee MDPI, Basel, Switzerland. This article is an open access article distributed under the terms and conditions of the Creative Commons by Attribution (CC-BY) license (http:/ / creativecommons.org/licenses/by/4.0/). 